\title{
On Some Theoretical Issues about Historical Strata Analysis
}

\author{
Pan Wuyun * \\ (Shanghai Normal University, China)
}

\begin{abstract}
This paper is a comprehensive discussion about a few theoretical issues of historical strata analysis, that is, uniformitarianism and neogramarian hypothesis, catastrophism and borrowing, wendu and baidu readings, native stratum, identification of loan strata and native stratum, influence and borrowing, and real time and apparent time.
\end{abstract}

Keywords: analysis of historical strata, theoretical issues

\section{Uniformitarianism and neogramarian hypothesis}

In 1785, James Hutton proposed the theory of uniformitarianism, which has become the theoretical cornerstone of modern geology. According to him, the landforms on the surface of the earth today are the results of long-term geological processes. The geological changes that occur now also has taken place from the time immemorial. The history of the Earth can thus be conjectured by observing the present-day geological changes. The theory of uniformitarianism can be summarized into one sentence: the present is the key to the past.

The most common and influential formula of uniformitarian is clearly related to gradualism. The surface features of the Earth today have resulted from minor but continuous processes such as corrosion, deposition, deformation, and orogeny, etc. which can be observed around the globe.

The linguistic uniformitarianism proposed by Willian Dwight Whitney casts a direct influence on the Neogrammarian School. The leading neogrammarian linguist Karl Brugmann (1897:1-2, c.f Labov (1994)) said:

"Among the many valuable contributions of William Dwight Whitney to linguistic science is one especially important and fundamental principle. It may be stated in these words. In explaining prehistoric phenomena of language we must assume no other factors than those which we are able to observe and estimate in the historical period of language development. The factors that produced changes in human speech five thousand years ago or ten thousand years ago cannot have been essentially different from those which are now

* Pan Wuyun: (1) Professor, Director of Research Institute of Linguistics, Shanghai Normal University, Shanghai, China. (2) Chief Researcher, e-Research Institute of Comparative Linguistics of Shanghai Universities, Shanghai, China. E-mail: pwy@ shnu.edu.cn. 


\section{Pan Wuyun}

operating to transform living languages."

As stated in the neogrammarian hypothesis, a sound change in a language is a regular and gradual process. If under the phonetic condition $\mathrm{C}$, phoneme $\mathrm{A}$ changes into phoneme $\mathrm{B}$, the formula of the sound change should be:

$\mathrm{A} \rightarrow \mathrm{B} / \mathrm{C}$ meaning: Phoneme A becomes Phoneme B under Condition C.

Two questions here to be explained first. One is why sound changes are gradual, and the other is why sound changes are regular.

\subsection{The first question now}

The following is a series of the Sketches describing a sound change. In diag.1, in certain historical period a group of words contain phoneme A with its particular pronunciation specifications. While in another period, phoneme A is changed to phoneme B with a different set of pronunciation properties. For instance, the rhyme $M o$ (模), pronounced /a/ in Old Chinese, was pronounced as /o/ in Middle Chinese. Such change could not have happened overnight from $/ \mathrm{a} /$ to $/ \mathrm{o} /$, as this kind of abrupt change in a short period of time would not make people intelligible.

Diag. 1

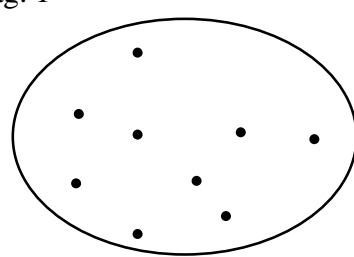

A

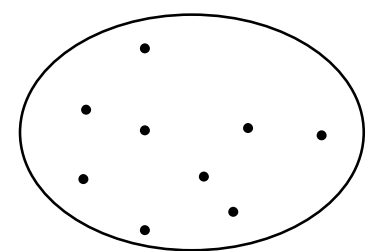

B

Diag. 3

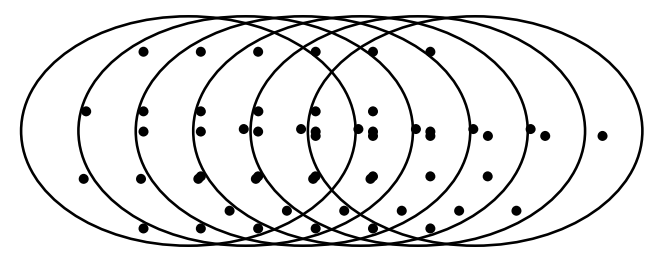

A $-\cdots-\cdots-\cdots-\cdots B$

A phoneme in a speech community consists of many allophones. Different people articulate the phoneme in different ways, and the same person may pronounce it differently at different times. Phoneme /a/ is thus a combination of many allophones. As shown in diag.2, within a short period of time, a phoneme has only minor variations. During the sound change from A to B, set B overlaps with set A with only one of its variants, $v$, becoming more and more distinctive in its sound properties. However, the variant $v$ does 


\section{On Some Theoretical Issues about Historical Strata Analysis}

not impede communications within the speech community. Thus, the qualitative change in diag.1 occurs only after numerous intermediate minor alterations have taken place as demonstrated in diag. 3 .

It can be inferred from the diagrams above that a sound change is in fact the change of sound value, and that a sound change has to be gradual. If phoneme $\mathrm{A}$ becomes $\mathrm{B}$ immediately, as shown in diag.1, people could not communicate with each other anymore. Besides, a sound change is possible only if it includes many intermediary deviations away from A and moving towards B, as illustrated in diag.3. Meanwhile, most of the allophones remain unchanged with little fluctuation in their phonetic value so that daily communication is not interrupted.

\subsection{The issue of regularity in sound changes}
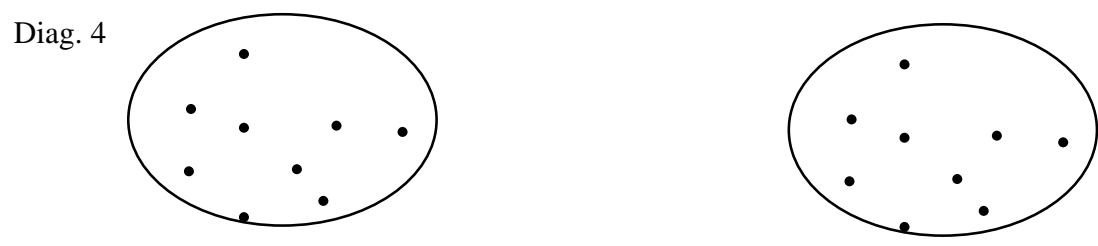

A1

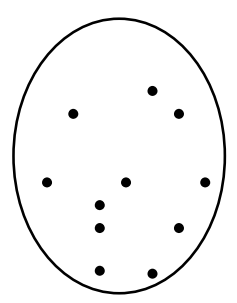

A2
B1

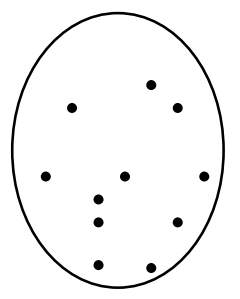

B2

In diag.4, A1 and A2 represent two different phonemes of a certain historical period. Each comprises a group of words which, relying on the phonemic boundaries, distinguish themselves from words of the other set and denote different meanings. A1 and A2 evolve into B1 and B2 respectively in a later period. Though the sound values of the two phonemes change, their phonemic boundaries remain distinct. If a word in A1 now somehow becomes evolved into B2 in pronunciation, it will find itself in a semantic conflict with some word in B2. Hereinafter, during the sound change process, all the variations of a speech sound will form together as one group and change simultaneously. This is the regularity of sound change.

The most important contributor to the sound change process is human vocal and hearing 


\section{Pan Wuyun}

organs. All the vocal organs collaborate with each other in producing a speech sound and thus affect each other. The interaction of these organs will lead to the change of speech sounds. When a person receives a sound, he/she might misinterpret it as another sound in some situations, which also causes sound changes. Hence, many sound changes can be explained with reference to human vocal and hearing organs. Therefore, sound changes for which vocal and perceptive factors account are called the natural process.

Since the vocal and hearing organs of human beings have barely changed since ancient times the natural processes of sound change remain largely the same in the present day. The sound changes that historical linguists discuss usually refer to natural processes which can be explained by articulation and perception, and described by the formula: $\mathrm{A} \longrightarrow \mathrm{B} / \mathrm{C}$. Here, $C$ has a functional relation in which $A$ is a variable. In a certain historical period of a language, any phoneme A will change to $\mathrm{B}$ in another period as long as it satisfies condition $\mathrm{C}$. The assumption builds up the theoretical foundation of the historical comparative method. Now we will look into the process of language splitting:

Diag. 5

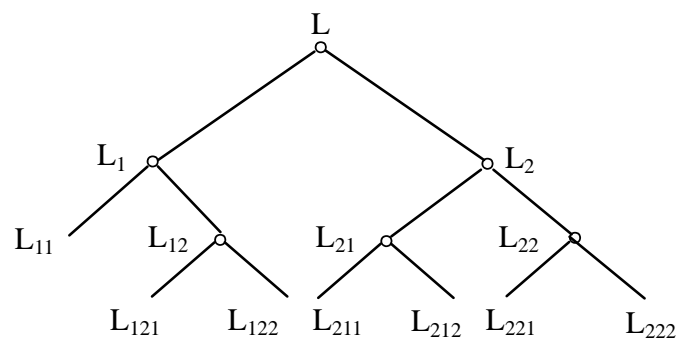

When language $L$ splits into branches $L_{1}$ and $L_{2}$, phoneme $P$ in $L$ becomes $P_{1}$ and $P_{2}$ in $\mathrm{L}_{1}$ and $\mathrm{L}_{2}$ respectively. Since the change is systemic, $\mathrm{P}_{1}$ and $\mathrm{P}_{2}$ share some phonetic properties, that is, $\mathrm{P}_{1}$ in $\mathrm{L}_{1}$ corresponds to $\mathrm{P}_{2}$ in $\mathrm{L}_{2}$. If only few words share phonetic correspondence in two languages, it might be caused by coincidence. But if there are a number of such words sharing phonemic regularities rather than by accident, it attests to the common historical origin of the two languages. If $\mathrm{P}_{1}$ and $\mathrm{P}_{2}$ share a common phonetic feature $\mathrm{F}$, it is very likely that $\mathrm{F}$ comes from their common parent language $\mathrm{L}$. Thus we can reconstruct the feature $\mathrm{F}$ in $\mathrm{P}$. It is the basic method o reconstruct proto-languages in historical comparison. It is noteworthy that as long as the languages are genetically related, they can be compared even if they exist in historical periods that are far apart from each other. If $\mathrm{L}_{1}$ and $\mathrm{L}_{222}$ in diag.5 share the feature $\mathrm{F}$, we can assume that $\mathrm{L}$ has the feature $\mathrm{F}$ since the common node is language $\mathrm{L}$. However, as $\mathrm{L}_{1}$ and $\mathrm{L}_{222}$ do not share nodes $\mathrm{L}_{12}$ and $\mathrm{L}_{21}$, we cannot allocated feature $\mathrm{F}$ to them.

\section{Catastrophism and borrowing}




\section{On Some Theoretical Issues about Historical Strata Analysis}

Catastrophism in geology, in contrast to uniformitarianism, holds that the earth surface is the product of sudden, violent events, such as the rapid formations of mountain ranges, volcanic eruptions, meteorite collisions, etc. It corresponds to the linguistic theory that external factors, such as migration and dominant languages, effect changes in a language.

The historical comparative method presented in diag.5 operates on such a precondition: there is one and only one origin for each language node. We name the evolution model as single-source evolution. The shared features of any two languages in the diagram originated from the shared node. The diagram shows that in comparing $\mathrm{L}_{21}$ and $\mathrm{L}_{22}$, for instance, $\mathrm{L}_{2}$ is the common source; and while comparing $\mathrm{L}_{121}$ and $\mathrm{L}_{22}, \mathrm{~L}$ is the common node. However, some linguists find it difficult to apply the method to the reconstruction of ancient sounds of peripheral Chinese dialects, the reason for which is that peripheral dialects have their own distinct histories of development.

Diag. 6

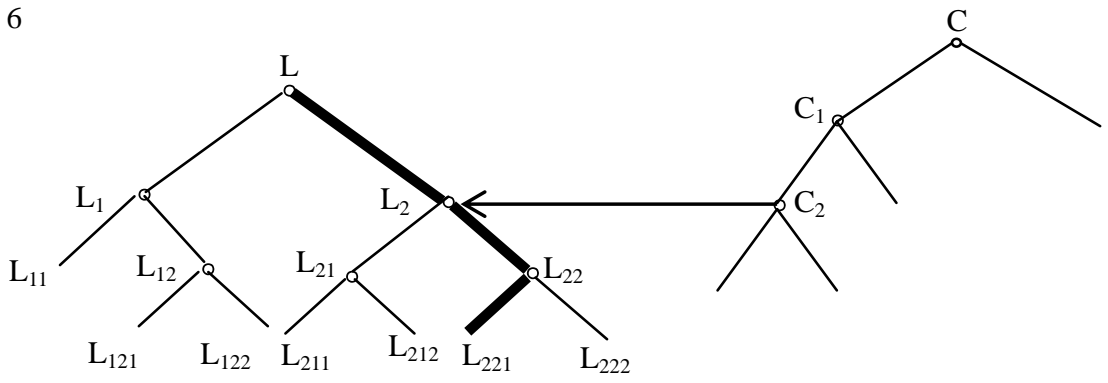

Zhongyuan, or the Central Plain, is the area on the lower reaches of the Yellow River which has long been the political and cultural center of China. As shown in diag.6, as the peripheral dialect keeps borrowing from the dominant Zhongyuan dialect $\mathrm{C}$, node $\mathrm{L}_{2}$ gets two sources, i.e. language $\mathrm{L}$ and loanwords from the dominant dialect $\mathrm{C}$. We call $\mathrm{L}$ the borrowing language (dialect), $\mathrm{C}$ the loan language (dialect), $\mathrm{L}_{2}$ the borrowing node, and $\mathrm{C}_{2}$ the loan node. To compare $\mathrm{L}_{21}$ and $\mathrm{L}_{222}$ in a diachronic way, the common features of the two languages will trace back to node $\mathrm{L}_{2}$ which has two different sources. That is to say, $\mathrm{L}_{21}$ and $\mathrm{L}_{222}$ either descend from their common protolanguage $\mathrm{L}$, or borrow from the dominant dialect $\mathrm{C}$. $\mathrm{L}-\mathrm{L}_{2}-\mathrm{L}_{22}-\mathrm{L}_{221}$ which demonstrates the internal evolution from dialect $\mathrm{L}$ to $\mathrm{L}_{221}$, and therefore represents what we call the native stratum. The stratum that borrows from another dialect, $\mathrm{C}$ in this case, is called the borrowing stratum. The purpose for historical strata analysis is to peel away the loan strata so as to show the native stratum ,therefore, paving the way for the application of historical comparative method.

Speaking of language $\mathrm{C}$, words that it loans to language $\mathrm{L}$ go through the changes from $\mathrm{L}_{2}, \mathrm{~L}_{22}$ to $\mathrm{L}_{221}$ together with $\mathrm{L}_{2}$. The loanwords, in this sense, are a dialect diverging from $\mathrm{C}$ at node $\mathrm{C}_{2}$. Therefore, $\mathrm{C}_{2}$ can be used to reconstruct languages $\mathrm{C}_{2}, \mathrm{C}_{1}, \mathrm{C}$ with other nodes 


\section{Pan Wuyun}

in the $\mathrm{C}$ family. For instance, the Kan-on and Go-on in Japanese, borrowed from the Chinese language, can be taken as a dialect of Chinese. Bernhard Karlgren uses the method to reconstruct the speech sounds of Middle Chinese.

A historical comparison of the borrowing language $\mathrm{L}$ requires no precise identification of when it borrows from the loan language, as the borrowing strata will always removed during the process. However, for that of the loan language $\mathrm{C}$, the time of the loan node needs to be specified as the loan strata is involved in the process of comparison. However, the materials from the loan strata are used simply for the reconstruction of linguistic features of languages preceding $\mathrm{C}_{2}$. For example, Kan-on were loaned from Chinese to Japanese in the Tang Dynasty (AD 618-907), and hence it merely helps to reconstruct Chinese before Tang Dynasty rather than after it.

Consequently, in the historical strata analysis, a precise period is difficult to define in many cases. So we adopt relatively ambiguous period names for description, such as the Old stratum, the Middle stratum, etc. In other cases, names that replace certain periods, like the stratum a, are used to denote that a class of sounds are loaned during period a.

The borrowing of the Chinese language is often relevant to Chinese characters. Chinese features trans-dialecticality, i.e. different Chinese dialects, related or even unrelated, adopt the unified system of Chinese characters in writing, despite their differences in pronunciation and usage of words in verbal communication. This feature of Chinese, plus with the recognition of Old and Middle Chinese sounds in Chinese dialectology, makes a Chinese character sometimes break away from its actual sound category. Though “他 (tā, 'he')" has the same final in rhyme Ma (麻) of Division II of Middle Chinese, but still people regard it as in the rhyme Ge (歌) of Division II as it apears in Guangyun (广韵). The following is the strata model of initial $R i$ (日) in Shanghai dialect.

As shown in the diagram, the pronunciation of initial $R i$ (日) in Shanghai dialect is, $/ \mathrm{n}_{0}-/$ during the period of Middle Chinese, remains unchanged till the present day. As an example, “日” in word “日脚 (rìjiăo, 'date')"reads as “nir?”. In some dominant dialect, however, initial $R i$ (日) has evolved to /z-/ through a process of $\mathrm{n}_{-}>K_{-}>\mathrm{z}_{-}>\mathrm{z}_{-}$. When Shanghai dialect borrows a word from the dominant dialect in a particular historical period, say, “日本 (rìběn, 'Japan')” whose “日 (rì)” is read as "ZZ”" in the dominant dialect, Shanghai dialect has to adopt the most highly similar sound "z-" to replace "zl", since there is no sound " $\mathrm{z}_{\mathrm{c}}$ " in the dialect. As /z-/ is the pronunciation of initial Xie (邪) in Shanghai dialect, the borrowed “日 (rì)" in the loanword “日本 (rìběn, 'Japan')" evolves with other characters of the Xie (邪) initial. Nevertheless, “日” as a Chinese character is deemed traditionally as initial $R i$ (日). Therefore, in the perspective of the borrowing party, i.e. in Shanghai dialect, $R i$ (日) initial is endowed with two strata: $/ \mathrm{n}_{\mathrm{o}}-/$ and $/ \mathrm{z}-/$. 


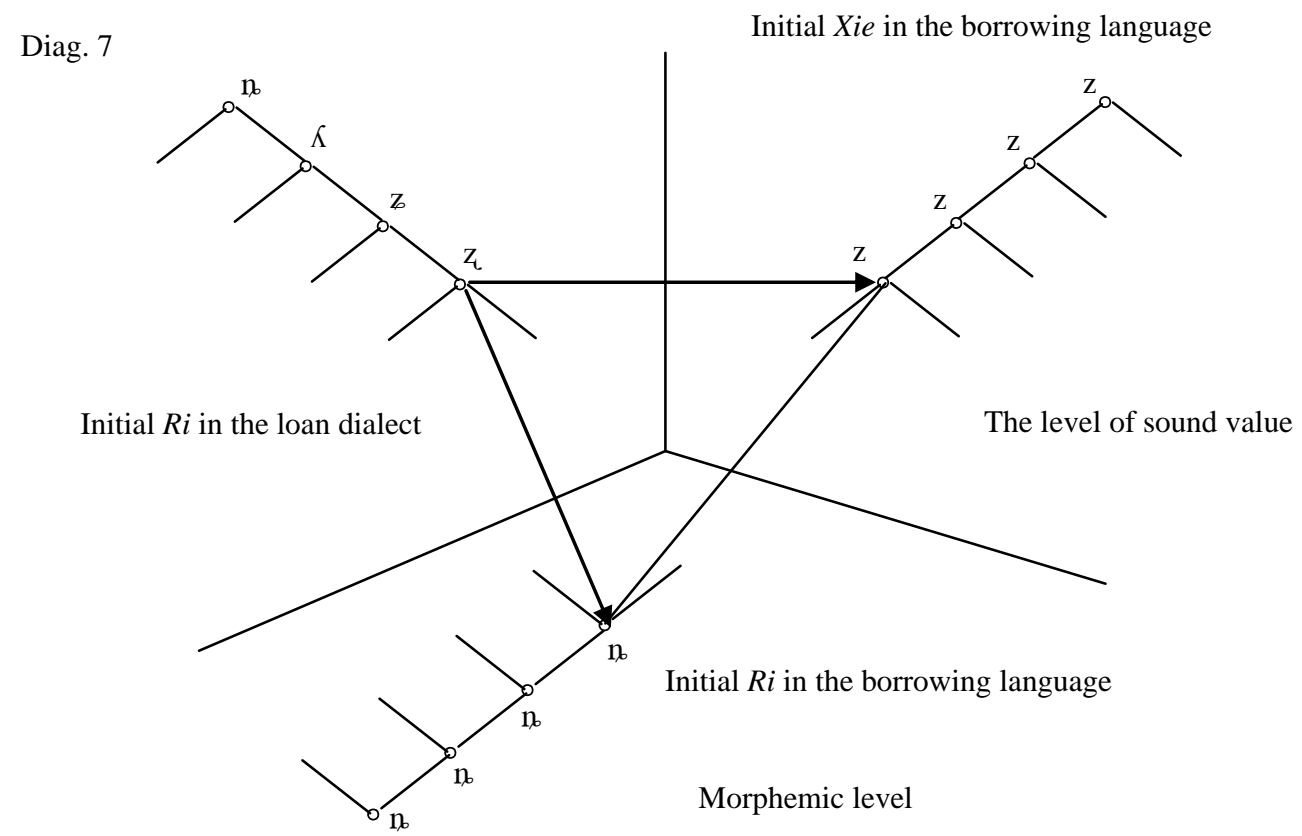

\section{Wendu（文读） and Baidu（白读） readings}

Wendu, "literary readings", is a special type of loan strata.

Dominant dialects came into being in some political, economic or cultural centers of ancient China, e.g. the Lin'an (临安) dialect spoken in the present-day Zhejiang (浙江) and Jiangsu (江苏) provinces of East China, Guangxin (广信) dialect in the present-day Guangdong (广东) and Guangxi (广西) provinces of South China, etc. They were the lingua franca for the upper class in these areas at one time, representing the standard pronunciation in the view of Chinese scholars. However, unlike schools today, academies in different dialect continua in ancient China could not teach in the authoritative dialect, they often taught in their own dialect instead. Therefore, if a sound class differed from that in the dominant dialect to a great extent, people tended to use the most highly similar sound to replace that in the dominant dialect. For example, “日 (rì)" in Wenzhou (温州) dialect was read as "ne ${ }^{8 "}(<$ ne? $)$ at the start. In Lin'an dialect at that time, the same character was pronounced very differently as "zip" ( $>\mathrm{z} P$ ? $)$. Wenzhou people thus used the closest equivalent sound " $3 \mathrm{i}$ ?" in their language to replace "zip", which became a wendu sound in their dialectical teaching and later on evolved to the sound "zai ${ }^{8}$ " in modern Wenzhou dialect.

Strictly speaking, literary readings are an interlanguage used by people of different 


\section{Pan Wuyun}

dialect continua to learn the dominant dialect. They are sounds of the dominant dialect transformed by the phonetic system of a non-dominant dialect. In communications carried out in dialects nowadays, students will use Mandarin if they encounter words and expressions that do not exist in their own dialect, such as “激光 (jīguāng, 'laser')" and “熵 (shāng, 'entropy')". It is the same case in the ancient academies. Since many characters in the Four Books and the Five Classics are unable to be pronounced in dialects, the teacher would turn to fanqie (反切) phonetic notation to indicate the pronunciation of the character. Teachers who had received education in the dominant dialect continuum would also bring pronunciations in the dominant dialect to their own dialect, which, after modifications by the phonetic system, became literary readings in the dialect.

Besides, due to the imperial examination system, scholars in ancient China demonstrated high value on the social conventions of the cultural and political centers in the Central Plain, which bred the genteelism worship and resulted in the large-scale loan of words from the dominant dialect when they taught. For instance, “学 (xué, "to study')" was read as

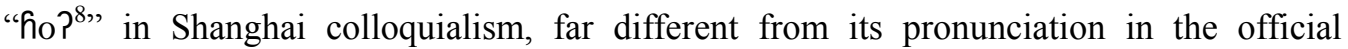
language at the time. Scholars in Shanghai regarded the latter as the standard and thus created a similar sound "jia ${ }^{8 "}$ " by using Shanghai phonetic system. At first, the sound "jia ?" $^{8}$ "was used only in schools to read classical texts. When Shanghai was opened as a trading port, new words flooded in from the West. Loanwords such as “文学 (wénxué, 'literature')" and "数学 (shùxué, 'mathematics')" were first used in the government's education departments, and scholars used "jia P $^{8}$ " to pronounce the character “学 (xué)" in these words. When the new words went to the broad society and were used by ordinary people, the pronunciation "jia ?" " of "学 (xué)" became a literal reading, in contrast to the baidu, or colloquial reading, of the character, that is, "ho?".

Intellectuals created sounds in order to distinguish the genteelism and the colloquialism. It is for sure that not all characters have literal readings. For the rhyme Jue (觉) of Shanghai dialect, the word “学乐 (xuéyuè)”, say, has a literal reading “jia?”. However “壳 (ké / qiào, "shell')" was pronounced only as "kho?"” without the corresponding literal reading "t6hia ?" " because “壳 (qiào)" was rarely used in traditional Chinese literal texts.

Apart from teaching, there were other sources for literal readings. The librettos and stage speeches in Chinese operas usually keep their distance with the spoken language so as to show the refined grace of arts. The yunbai (韵白), a form of heightened speech, of Sheng (生) and Dan (旦) roles in Jingju (京剧) are different from the Beijing colloquialisms. The phrase “刑部堂 (xíngbùtáng, 'the Hall of the Ministry of Punishment')” is sung as “jin ${ }^{4} \mathrm{bu}^{21} \mathrm{dan}^{21}$ " in Ouju (瓯剧), a form of Chinese opera from Wenzhou, East China's Zhejiang province whereas it is articulated as " $\mathrm{jay}^{4} \mathrm{bu}^{21} \mathrm{duo}^{21}$ " in modern Wenzhou dialect. The former is closer to the northern dialect in terms of its finals. 
Religions are another source that produces literal readings. I heard my grandmother chant the Heart of Prajna Oaramita Sutra when I was young and the beginning sentence was “行深般若波罗蜜多时 (xíng shēn Pánruò Bōluómìduō shí, “when Bodhisattva Avalokiteshvara was practicing the profound Prajna Paramita...')". “行 (xíng)" should be pronounced the same as “形 (xíng)", which is different from its pronunciation in Wenzhou dialect, that is, Division II of rhyme Geng (庚) with the initial consonant Xia (匣). It is likely that at the time when the monk first brought the Buddhist classic to Wenzhou, the rhyme Geng (庚) in his dialect had already syncretized with the rhyme Qing (青). The Buddhist believers in Wenzhou regarded the pronunciation of that senior monk as the standard and followed the reading. The sound is preserved in the language till the present day.

Literal readings sometimes have more than one dialectical source. Nearly all the literal readings of Cangnan Manhua (苍南蛮话), a dialect spoken mainly in Cangnan county of Wenzhou are from Pingyang (平阳) dialect. As Cangnan was previously part of Pingyang county, children from its rural areas usually went to school in the county seat of Pingyang. Students were taught in Pingyang dialect, which was how the literal readings were brought to Cangnan Manhua.

A literal reading, whatever its sources might be, is a kind of loanword in nature. The loaning of words is actually the process of learning from the loan language. In this sense, literal readings are the social interlanguage in second language acquisition. Consequently, the formation of a literal reading has to conform to the following two principles:

1) The principle of maximal similarity

2) The principle of minimal alteration

When a person borrows a word from another language, he often tries to articulate the sound with the highest similarity as much as posssible. However, the interference from the mother language persists and will inevitably lead to alterations of the original pronunciation in the target language. The literal reading and the interlanguage in second language acquisition are therefore very much alike except that the latter is quite individualized whereas literal readings are a social phenomenon. If the pronunciation of a loanword is different from that in the mother language, the person needs to make alterations in the mother language so as to make two pronunciations alike. Nevertheless, any alterations should adhere to the principle of economy, that is, to alter as little as possible as long as the pronunciation does not impede communication.

According to the principle of minimal alteration, the pronunciation of a loanword should adopt the original consonant, vowel and tone of the borrowed dialect as far as possible. For instance, “卸” (to unload) in Wenzhou dialect is borrowed from Shanghai with some alterations in pronunciation. Originally, the character is pronounced as " $\mathrm{cia}^{5}$ ". Since there is 


\section{Pan Wuyun}

no long medial sound "i" in the Wenzhou phonetic system, the sound "i" has to be either shortened or omitted, which leads to the pronunciation "ca". Besides, the tone has changed to the falling tone in Wenzhou dialect. Another example is the $R i$ in Shanghai dialect. The form of the initial consonant in the loan language, that is, Chinese Mandarin, is kept while the pronunciation has changed to $/ 1-/$, an existing phoneme in the phonetic system of Shanghai dialect. Still, no new phonemes are created.

However, for some languages, new initial consonants or final vowels will be introduced in the process of borrowing. For example, in the Shui (水) language ${ }^{\circledR}$, phoneme $/ 1 /$ did not exist at the start. When borrowing words with the final $/ 1 /$ from the Chinese dialect, it preserved the phoneme. “思想 (sīxiăng, 'thoughts')”, say, is pronounced as “spsja:n” in the language. Yet the newly introduced final has not been incorporated to its phonetic system, rather, it is used only in loanwords from the Chinese dialect. In this sense, the new phoneme does not upset the existing phonetic structure of the language.

3) The unit of borrowing is the word.

On the surface, literal readings relate solely to the pronunciations of characters. However, as a special type of loanwords, they correlate with specific words when being borrowed into another dialect. This is because the unit of borrowing is a word rather than character. An example is the word “认识 (rènshi, 'to make the acquaintance of')" in Shanghai dialect. According to the newest variety of the dialect, the word is pronounced as " $12 n{ }^{6} \mathrm{se}^{7}$ ". Compared with the pronunciation in the old variety, it has merely altered the sound of the character “认 (rèn)" with that of “识 (shí)” unchanged. On the surface, it seems that the unit of borrowing is a character. Yet in truth, the pronunciation of the initial $R$ of the newest variety, i.e. $/ 1-/$, is related only to specific words. That is, though the initial $R$ of the character “认 (rèn)" in “认识 (rènshi)" is pronounced as "l-", the same initial is pronounced as “n.". in the word “认得 (rèndé, “to know about')" (“nin ${ }^{6}$ te? ? ").

4) The minimal phonetic unit of borrowing is a syllable.

In dialects, the literal and colloquial readings of a word usually differ only in one of the following three aspects: the initial consonant, final vowel and tone. Therefore, many scholars assume that the basic phonetic unit that distinguishes the literal reading from a colloquial reading is the initial, final or the tone rather than the syllable. Since literal readings are formed in the process of borrowing, the postulate seems to be correct. For instance, in Wenzhou dialect, the literal reading of "问 (wèn)" is "van ${ }^{6}$ " while its colloquial reading is "man ${ }^{6}$ ". The two types of reading differ merely in their initials. It seems that when the literal reading was introduced, only the initial /v-/ was borrowed.

The truth is that the modern pronunciation "man ${ }^{6}$ " is derived from "mən ${ }^{6}$ " in old

\footnotetext{
(1) The Shui language is a Tai-Kadai language spoken by Sui people of West China's Guizhou province.
} 


\section{On Some Theoretical Issues about Historical Strata Analysis}

Wenzhou dialect. In some dominant dialect at that time, “问 (wèn)” was pronounced as "vən" ${ }^{6}$ ". When ancient Wenzhou people borrowed the pronunciation from the dominant dialect, they would naturally borrow the whole syllable, i.e. "vən" "which shared a similar final vowel with " $\operatorname{mon}^{6}$ " in their own Wenzhou dialect. Later on, "vən " ${ }^{6}$ " evolved to "van " which became the literal reading of the character, while "mən" ${ }^{6}$ " evolved to "man", the corresponding colloquial reading. To compare the literal and colloquial readings simply in terms of the form, it is very likely to come to the easy conclusion that merely the initial was borrowed.

The relationships between the borrowing language and the loan language have provided an important method to reconstruct ancient dialects. For instance, some character is pronounced as " $\mathrm{I}_{1} \mathrm{~F}_{1}$ " 11 in dialect $\mathrm{D}$ and as " $\mathrm{I}_{2} \mathrm{~F}_{2}$ " in the borrow dialect $\mathrm{C}$. We already know that in the period of borrowing, the pronunciation of the character in dialect $\mathrm{C}$ was " $\mathrm{I}_{20} \mathrm{~F}_{20}$ ". Its pronunciation in dialect $\mathrm{D}$ in the period of borrowing $\mathrm{I}_{10} \mathrm{~F}_{10} 0$ can thus be reconstructed with the following relations:

$$
\begin{aligned}
& \mathrm{I}_{10}>\mathrm{I}_{1}, \mathrm{~V}_{10}>\mathrm{V}_{1} \\
& \mathrm{I}_{20}>\mathrm{I}_{2}, \mathrm{~V}_{20}>\mathrm{V}_{2} \\
& \left.\mathrm{I}_{10} \approx \mathrm{I}_{20}, \mathrm{~F}_{10} \approx \mathrm{F}_{20} \quad \text { (““ } \approx " \text { stands for being approximate to }\right)
\end{aligned}
$$

Take the above-mentioned Chinese character "日 (ri)" as an example. Literal reading in Wenzhou dialect has very likely come from ancient Lin'an dialect. The modern literal reading of “日 (ri)" is "zai” in Wenzhou dialect while it is "ze?" in Hangzhou (杭州) dialect. It is already known that Hangzhou dialect descends from ancient Lin' an dialect and again the ancient official Lin'an dialect evolved from the official Bianjing (泣京) dialect of Song (宋) Dynasty (960-1279). In Huangji Jing Shi (皇极经世),by Shao Yong (邵雍), “日 (ri)" belongs to a same rhyme in this book with the characters in rhyme group Zhi (止) in Guangyun (广韵). And the final vowel of “日 (ri)” is “i” according to Menggu Ziyun (蒙古 字韵). Therefore the pronunciation of the character is highly possible to be " $\mathrm{il}$ " or " $\mathrm{\lambda i}$ ?" in Bianjing dialect at that time.

In light of the pronunciation "ze?" in modern Hangzhou dialect, “日 (ri)" is highly possible to be pronounced as "zip" in ancient Lin'an dialect. As there was no sound " $\lambda$ " in the phonetic system of the latter, the closest equivalent sound " $z$ " was used to replace the sound " $\lambda$ " borrowed from the official dialect of the Central Plain. Since old Wenzhou dialect was from the official Lin'an dialect, it is reasonable to infer that the final "ai" in the literal reading of “日 (rì)", i.e. "zail", was derived from "-i".

\footnotetext{
(1) Please note that $I$ stands for the initial consonant and $F$ for the final consonant.
} 
Pan Wuyun

Diag. 8 The Respective wendu and baidu Sources for “日” in Wenzhou(温州) Dialect

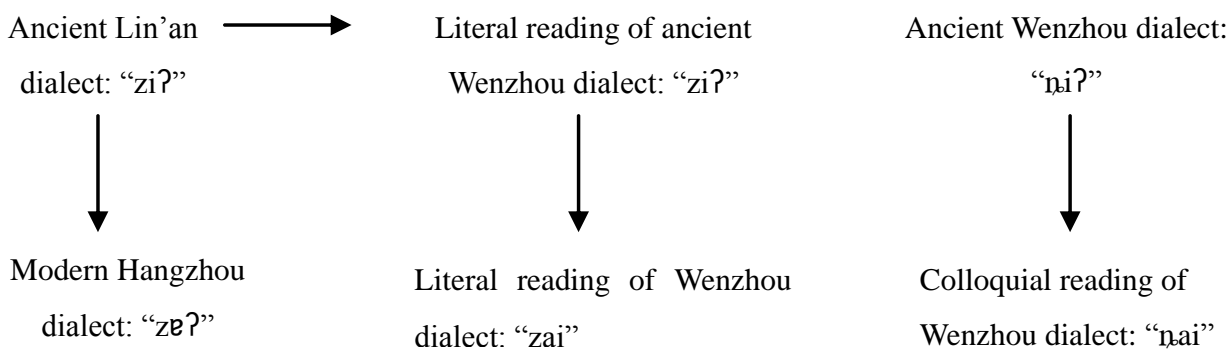

In addition to the historical comparative method and the internal reconstruction, there is a third method for the reconstruction of ancient sounds, i.e. the historical strata analysis.

The existence of both literal and colloquial readings usually appears in certain sound classes but not in other sound classes. Take the Northern $\mathrm{Wu}$ dialect as an example. Characters of the initial Ri (日) or Wei (微) have both literal and colloquial readings while those with initial Bang (帮), Ding (定), or Jing (精) have only colloquial readings. As for finals, rhyme Hao (豪) does not have both literal and colloquial readings. The rhyme Yao (肴) does but only in characters that are in the initial consonant series Jian (见). It helps to explain the unbalanced allocation of literal and colloquial readings in different initials and finals. During the historical period when the literal readings were borrowed, initials Bang (帮), Ding (定), Jing (精) and the rhyme Hao (豪) were pronounced almost the same in the Northern mandarin $\mathrm{Wu}$ dialect as that in the dominant dialect.

On the other hand, initial Wei (微) was pronounced as /m-/ in Wu dialect while it was read as $/ \mathrm{v}-/$ in the dominant dialect. And the initial $R i$ (日) was pronounced as $/ \mathrm{n}_{-} /$but in the dominant dialect it was $/ \lambda-/$. Again, the pronunciation of the initial consonant series Jian (见) of rhyme Yao (肴) was /-au/ in Wu dialect but/-iau/ in the dominant dialect. In view of the eminent differences, Wu dialect had to use literal readings which were different from its exiting pronunciation to imitate the dominant dialect.

The more literal readings there were in a dialect, the greater the dialect differed from the dominant dialect in a historical period. It explains why the Southern $\mathrm{Wu}$ dialects have more literal readings than Northern $\mathrm{Wu}$ dialects and Fujian (福建) dialect has more than $\mathrm{Wu}$ dialect.

There are sometimes several literal readings for one Chinese character in some dialects, which is attributed mainly to two causes. First, more than one dominant dialect affected the development of the dialect. Second, the dialect has received the influence of a dominant dialect in several different historical periods. 


\section{Native stratum}

If the loan stratum is removed from a language, the rest of its vocabulary belongs to the native stratum. The sound changes that we study are mainly natural processes in a language's native stratum.

In a language, the rule of sound change may affect all the words of the phonetic class where a particular sound change occurs. The results of the sound change, as the New Grammarian School has put it, are pre-determined with no exceptions. Nonetheless, a language is to some extent a multi-dimensional phonological space. The sound change of a group of words that belong to the same sound class cannot be attributed only to phonetic causes. Other factors also function in the process with each of them having a different orientation. Thus, words of the sound class may register different changing speeds, as shown in the following diagram.

Diag. 9

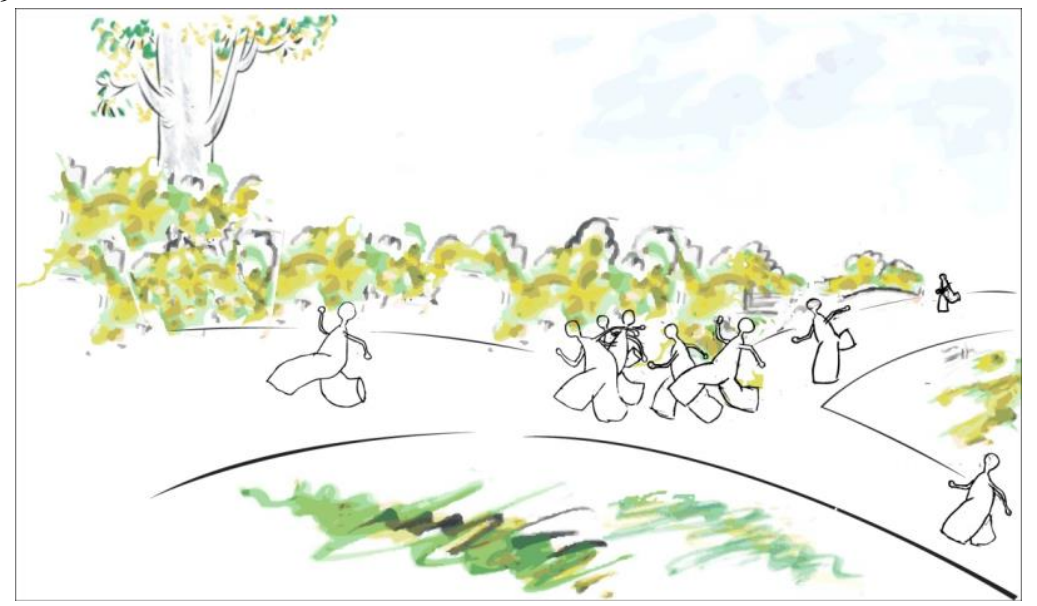

The individuals in the diagram symbolize individual words in a sound change. People on the major running track represent the native stratum while the person from the side way is the loan stratum. Some people run fast, so they stand for the lead stratum. Some stay behind and they are the lagging stratum. The group with the most people is called the main stratum. Take rhyme $G e$ (歌) in the Beijing dialect as an example. Many characters of the rhyme with an alveolar initial are pronounced as "-uo", which forms the main stratum of its kind. As a high-frequency word, “他 (tā, 'he / him')" becomes part of the lagging stratum. All these characters represent the many phases in the chain shift: $a>0>0>$ uo. When the main stratum evolves to the phase /-uo/, the pronunciation of "他 (tā)" remains in the phase of /-a/. Another example is the characters of rhyme $M a$ (麻) with a labial initial in the Shanghai dialect. The main stratum is the pronunciation /o/. However the rhyme in the 
latest variety of the dialect has evolved to /-u/, which becomes the lead stratum. Both /-o/ and $/-\mathrm{u} /$ are two phases of the chain shift: $\mathrm{a}>\mathrm{o}>\mathrm{u}$.

The lead, main, and lagging strata in the native stratum represent different phases of a sound change, which also indicate the lexical diffusion of the sound change.

\section{Distinction between loan strata and native stratum}

Since historical comparison can proceed only within the native stratum, it is necessary to identify the loan strata and the native stratum. However, a historical sound class sometimes has several different pronunciations in a dialect, which makes it difficult for us to makes distinction between loan strata and the lead strata or the lagging strata. For instance, $/-\mathrm{u} /$ is the main stratum of rhyme $G e$ (歌) in Shanghai dialect. Yet, some characters of the rhyme is pronounced as /-a/, e.g. “破 (pò, 'to break')" is pronounced as "pha”, and “拖 (tuō)” in “拖鼻涕 (tuō bítì, 'to blow your nose')" is pronounced as "tha”. Are these words borrowed? Or are they a special substratum of the native stratum? Another example is the rhyme $Y u$ (鱼) in Wu dialect. The rhyme has two important historical strata: the rounded sounds and the un-rounded sounds. The former is usually deemed as a colloquial reading while the latter a literal reading. That is, the former is a native stratum in $\mathrm{Wu}$ dialect while the latter is borrowed from Northern Mandarin. Nonetheless, it is also reasonable to deem the latter as the native stratum with the former only the lagging stratum of a sound change.

Seeing only the different readings of a historical sound class, we sometimes feel it hard to identify the strata to which the pronunciations belong. Consequently, certain general methods are required.The following are the methods of identification we put forward.

\subsection{The basic words and cultural words in the vocabulary}

Most loanwords are cultural words. The basic words of a language, especially the core words, are difficult to borrow. According to statistics, around $76 \%$ of the English vocabulary today is not from the Old English but loanwords borrowed from other languages (Thomason, Sarah Gray and Terence Kaufmann, 1988). However, the percentage drops to some $10 \%$ in the basic lexicon and $90 \%$ of the basic English words come from the Old English (ibid.). If a stratum includes none of basic words, it is definitely a loan one. For instance, initial $R i$ (日) in the Shanghai dialect has two strata: $/ \mathrm{n} /$ and $/ \mathrm{z} /$. The former comprises nearly all the basic words of the rhyme while the latter all the non-basic words at that time. "人 (rén, "human beings')" is pronounced as "n--" while the same character in the loanword “人民 (rénmín, "the people')" is pronounced "z-". “日 (rì)” in the basic word “日脚 (rijiăo, 'date')" is read as " $n$ ”" but the pronunciation is " $z-$ " in the loanword “日 本 (riběn, 'Japan')". It thus can be concluded that $/ z-/$ is the loan stratum whereas $/ n_{-} /$is the native stratum. In the latest variety, the initial has also borrowed the sound /l-/ from 


\section{On Some Theoretical Issues about Historical Strata Analysis}

Mandarin, such as “染布 (rănbù, 'cloth dyeing')”, “富饶 (füráo, ‘fertile’)”, “打扰 (dărăo, 'to interrupt')”, “绕圈子 (rào quānzi, 'to beat about the bush')”, to name but a few. All these loanwords are not basic words of Shanghai dialect (Gu Qing, 2004).

A stratum comprises mainly three kinds of words: non-basic words, including cultural words, basic words, and words both basic and non-basic, which, for now, are called common words. Suppose there are two strata in a dialect and at least one of them contains common words. Say A is the stratum that we already know includes common words. Then the composition of $\mathrm{B}$ has the following possibilities:

Table 1. Two Strata in a Dialect

\begin{tabular}{|c|c|c|c|}
\hline & Possibility 1 & Possibility 2 & Possibility 3 \\
\hline A & Common words & Common words & Common words \\
\hline B & Non-basic words & Basic words & Common words \\
\hline
\end{tabular}

In possibility 1, stratum B contains only non-basic words and if so, it is definitely a loan stratum. An example is the strata /z-/ and /l-/ of initial $R i$ (日) in Shanghai dialect. However, for possibility 2 and 3, B is difficult to identify.

There are no clear lines of demarcation between basic and non-basic words. Besides, even a basic word can also be a loanword. Therefore, we cannot identify strata only by the basic and non-basic words in a stratum without taking other factors into comprehensive consideration.

\subsection{The number of characters in different strata}

In a language, the basic words are usually quite stable and their survival rate is considerably large. But surely the native stratum can be gradually replaced by the loan stratum if a dialect keeps borrowing from the dominant dialect. Nonetheless, examining its peripheral dialects, we will find that in those relatively conservative dialects, the native stratum is well preserved. Hence, there should be certain correlations between the number of characters of the native stratum and that of the loan strata. As some sound classes in Wu dialects have clear and definite lines of demarcation between the native and loan strata, we'll take them as examples. ${ }^{(1)}$

Table 2. Initial Ri (日)

\begin{tabular}{|c|c|c|}
\hline Dialects & $\begin{array}{c}\text { Number of characters of the loan } \\
\text { stratum (fricative consonants) }\end{array}$ & $\begin{array}{c}\text { Number of characters of the native } \\
\text { stratum (nasal consonants) }\end{array}$ \\
\hline Shanghai & 43 & 38 \\
\hline Shaoxing & 18 & 20 \\
\hline
\end{tabular}

\footnotetext{
(1) The data of Wenzhou is from Pan Wuyun (1999). Data of Longquan is from the field investigation conducted by Pan Wuyun. Data of Xianju and Suichang come from Dai Shaoming (2003) and Cao Zhiyun (2000). Other data is provided by Qian Nairong (1992).
} 
Pan Wuyun

\begin{tabular}{|l|l|l|}
\hline Suzhou & 50 & 28 \\
\hline Wenzhou & 75 & 31 \\
\hline Huangyan & 27 & 18 \\
\hline Ningbo & 22 & 30 \\
\hline Xianju & 26 & 21 \\
\hline Longquan & 9 & 51 \\
\hline Suichang & 10 & 36 \\
\hline
\end{tabular}

Table 3. Initial Wei (微)

\begin{tabular}{|l|c|c|}
\hline Dialects & $\begin{array}{c}\text { Number of characters of the loan } \\
\text { stratum (labiodental consonants) }\end{array}$ & $\begin{array}{c}\text { Number of characters of the native } \\
\text { stratum (bilabial consonants) }\end{array}$ \\
\hline Shanghai & 35 & 21 \\
\hline Shaoxing & 20 & 14 \\
\hline Suzhou & 34 & 19 \\
\hline Wenzhou & 43 & 28 \\
\hline Huangyan & 19 & 7 \\
\hline Ningbo & 26 & 11 \\
\hline Xianju & 24 & 13 \\
\hline Longquan & 3 & 29 \\
\hline Suichang & 5 & 25 \\
\hline
\end{tabular}

Table 4. Initial Consonant System Jian (见), Rhyme Yao (肴)

\begin{tabular}{|l|c|c||}
\hline Dialects & $\begin{array}{c}\text { Number of characters of the loan } \\
\text { stratum (sharp consonants) }\end{array}$ & $\begin{array}{c}\text { Number of characters of the native } \\
\text { stratum (round consonants) }\end{array}$ \\
\hline Shanghai & 28 & 22 \\
\hline Shaoxing & 8 & 10 \\
\hline Suzhou & 24 & 22 \\
\hline Huangyan & 7 & 13 \\
\hline Ningbo & 24 & 20 \\
\hline Xianju & 0 & 22 \\
\hline Wenzhou & 1 & 38 \\
\hline Longquan & 1 & 24 \\
\hline Suichang & 8 & 18 \\
\hline
\end{tabular}

From the above charts, we can conclude that the dominant Northern Mandarin influenced Northern $\mathrm{Wu}$ dialects more than Southern $\mathrm{Wu}$ dialects. In such varieties of the Northern $\mathrm{Wu}$ as Shanghai dialect, the number of characters of the loan stratum has outnumbered that of the native stratum. But despite that, the native stratum still features a 


\section{On Some Theoretical Issues about Historical Strata Analysis}

large number of characters. The Southern Wu dialects, as they received fewer impacts from the Northern Mandarin, have much more characters in the native stratum than those in the loan stratum.

Characters of the initial consonant series Jian (见), rhyme $Y u$ (鱼) are pronounced either with an open vowel or with a close vowel. The open/closed distinction divides the characters into two strata. Scholars usually regard the former as the colloquial reading while the other literal reading which is borrowed from the dominant Northern Mandarin.

Table 5. Two Strata in Characters of the Initial Consonant Series Jian (见), Rhyme Yu (鱼)

\begin{tabular}{|l|c|c|}
\hline \hline Dialects & $\begin{array}{c}\text { Number of characters with } \\
\text { a close vowel }\end{array}$ & $\begin{array}{c}\text { Number of characters with } \\
\text { an open vowel }\end{array}$ \\
\hline Shanghai & 35 & 3 \\
\hline Shaoxing & 11 & 1 \\
\hline Suzhou & 30 & 5 \\
\hline Wenzhou & 40 & 4 \\
\hline Huangyan & 11 & 4 \\
\hline Ningbo & 23 & 3 \\
\hline Xianju & 21 & 6 \\
\hline Longquan & 19 & 6 \\
\hline Suichang & 16 & 15 \\
\hline
\end{tabular}

In terms of the number of characters, the pair of loan and native strata is quite a contrast to its counterparts above. Even in the relatively conservative Southern Wu dialects, there are few open-vowel characters that supposedly comprise the native stratum. Therefore, doubts arise as whether the close-vowel characters belong to the loan stratum.

5.3 If two different strata do not share the relationship of same chain, one of them is the loan stratum.

The lagging, main and lead strata all resulted from their own sound changes. The lead stratum changes faster than the main stratum while the lagging a bit slower. Therefore, they are different phases of the same natural chain shift. We use the term "relationship of same chain" for them.

An example is the rhyme Ge (歌) in Beijing dialect. In the Han (汉) Dynasty (206 BC-AD 220), the rhyme was pronounced as /-ai/. When the coda was lost, the final was raised and backed: ai $>a>a>0>0$. The main stratum of the rhyme is now $/ 0 /(>\gamma)$. But the change in such high-frequency words as “大 (dà, 'big')”, “他 (tā, 'he / him')”, “那 (nà, 'that')" takes place a bit slowly. Being still pronounced as "a", they make up the lagging stratum. 


\section{Pan Wuyun}

Diag. 10

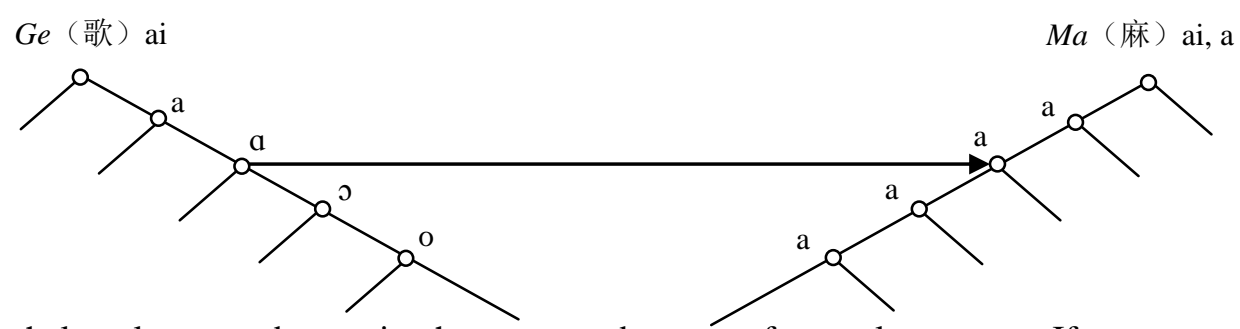

Nevertheless, language borrowing happens not because of natural processes. If two strata share no relationship of same chain, one of them must be the loan stratum. For instance, strata /no-/ and /z-/ of initial Ri (日) in Shanghai dialect do not belong to the same chain shift. It is later proved that /z-/ is the loan stratum.

\subsection{Loanwords are independent of any phonetic conditions.}

The borrowing from one language to another occurs out of the need of communication and cultural exchanges. It is independent of any phonetic conditions. To borrow only a velar consonant or a nasal vowel is almost impossible. Hence, if the pronunciation of a stratum relates only to phonetic conditions, it cannot be the loan stratum.

In dialects of southwest Zhejiang province, rhyme $Y u$ (鱼) has a stratum that shares the same pronunciation with rhyme $M a$ (麻).

Table 6. A Stratum of Rhyme Yu (鱼) Which Shares the Same Pronunciation with Rhyme Ma (麻) in Dialects of Southwest Zhejiang Province

\begin{tabular}{|c|c|c|c|c|c|c|c|c|c|c|}
\hline & & Kaihua & Changshan & Yushan & Longyou & Suichang & Yunhe & Qingyuan & Longquan & Songyang \\
\hline \multirow{3}{*}{$\begin{array}{l}\text { Rhyme } \\
Y u \text { (鱼) }\end{array}$} & 猪(pig) & $\mathrm{to}^{1}$ & $\mathrm{ta}^{1}$ & $\mathrm{ta}^{1}$ & tua $^{1}$ & $\mathrm{ta}^{1}$ & & $\mathrm{do}^{1}$ & to ${ }^{1}$ & tuə ${ }^{1}$ \\
\hline & 锄(to hoe) & $\mathrm{zo}^{2}$ & $\mathrm{za}^{2}$ & $\mathrm{za}^{2}$ & $\mathrm{zua}^{2}$ & $\mathrm{za}^{2}$ & $\mathrm{zO}^{2}$ & $\mathrm{so}^{2}$ & $\mathrm{so}^{2}$ & suə $^{2}$ \\
\hline & 梳(comb) & so ${ }^{1}$ & $\mathrm{sa}^{1}$ & $\mathrm{sa}^{1}$ & sua $^{1}$ & $\mathrm{sa}^{1}$ & & & so ${ }^{1}$ & sù $^{1}$ \\
\hline $\begin{array}{l}\text { Rhyme } \\
M a(\text { 麻 })\end{array}$ & 茶(tea) & $\mathrm{dz \vartheta ^{2 }}$ & $\mathrm{dza}^{2}$ & $\mathrm{dza}^{2}$ & $\mathrm{dzua}^{2}$ & $\mathrm{dza}^{2}$ & $\mathrm{dzao}^{2}$ & $\mathrm{tso}^{2}$ & $\mathrm{tso}^{2}$ & dzuə2 ${ }^{2}$ \\
\hline
\end{tabular}

The stratum is different from other strata of the rhyme $Y u$ (鱼), which are compared in the following chart.

Table 7. Other Strata of the Rhyme Yu (鱼) in Dialects of Southwest Zhejiang Province

\begin{tabular}{|c|c|c|c|c|c|c|c|c|c|}
\hline & Kaihua & Changshan & Yushan & Longyou & Suichang & Yunhe & Q Qingyuan & Longquan & Songyang \\
\hline 莫 (ramie) & $\operatorname{die}^{6}$ & $\mathrm{de}^{4}$ & $\mathrm{de}^{4}$ & $\mathrm{dz}^{2}$ & $\mathrm{~d}_{3} \mathrm{ie}^{4}$ & $d 3 y^{4}$ & toy $\mathrm{y}^{4}$ & $16 y^{4}$ & $\mathrm{dz} \mathrm{e}^{4}$ \\
\hline 初(beginning) & tshui ${ }^{1}$ & tshi $^{1}$ & $\mathrm{tsu}^{21}$ & $\operatorname{tshu}^{1}$ & tshur ${ }^{1}$ & tshu $^{1}$ & $\operatorname{tsh} \gamma^{1}$ & tshəщ' ${ }^{1}$ & $t^{t s h} w^{p 1}$ \\
\hline
\end{tabular}

In the above dialects, the same sound class has more than one pronunciation. Take the Suichang (遂昌) dialect as an example. Both “梳 (shū, 'comb”)” and “蔬 (shū, "vegetable')" are characters of initial Sheng (生) of rhyme Yu (鱼). But the former is 


\section{On Some Theoretical Issues about Historical Strata Analysis}

pronounced as "sa" " while the latter as "sur", classified into two different historical strata. Some scholars maintain that the former belongs to the Old Chinese stratum which was covered by the Middle Chinese stratum borrowed from the North, and that the few left uncovered remain to be pronounced in rhyme $M a$ (麻).

However, it is for sure that certain phonetic conditions have functioned in the sound change as the stratum exists only in the initial series Zhi (知) and Zhuang (庄). If the viewpoint of the scholars held is true, then why the coverage manifests a phonetic selectivity? Why are the initial series Zhi (知) and Zhuang (庄) uncovered?

\section{Influence and borrowing}

When words of language $\mathrm{A}$ are loaned to language $\mathrm{B}$, the process demonstrates a kind of influence, which is not equivalent to language borrowing.

Many Southeast Asian languages bear a tone system. These tonal languages are usually spoken in areas adjacent to the Chinese-language area. For instance, the South Asian languages outside China do not have tone systems while those inside China start to have. The Austronesian languages do not have tone systems but in the Huihui (回辉) language.After being brought to South China's Hainan province, tones begin to form. The development of tones in these languages is mainly due to the impacts from the Chinese language. Nonetheless, the sound change is not a language borrowing but the result of natural evolution, for the simple reason that the appearance of tones is related to phonetic conditions. Language borrowing is independent of any phonetic conditions.

The acute and heavy tones in Vietnamese derived from ancient words with the glottal stop - ?, and asking and tumbling tones from words ending in /-s/ (Haudricourt, 1954). Similar phonetic conditions also contributed to the rise of tones in the Tai language (Wang Jinliu, 1983). The appearance of tones in Burmese, like the previous two languages, again relates to codas. For instance, the tone ":" was formerly written as the coda /-h/ in Bagan-era stone inscriptions (Wang Danian, 1988). The emergence of tones in these languages, consequently, is a kind of internal sound change, and the Chinese language is simply a trigger that touches off the development of a tone system.

The devoicing in $\mathrm{Wu}$ dialect is influenced by peripheral dialects. Although most $\mathrm{Wu}$ dialects still preserve voiced fricatives, devoicing has already taken place in some of the varieties, such as the Jintan $\mathrm{Wu}$ and Nantong Wu which are geographically proximate to the official dialect, as well as the Longquan $\mathrm{Wu}$ and Qingyuan $\mathrm{Wu}$ that are geographically close to Min and Gan Chinese. The change can be explained only by linguistic influence.

But the devoicing of voiced soundsis a universal linguistic phenomenon. Physical structure of articulation also contributes to the change. The process of devoicing also started in the kernel area of Wu dialect where there was no influence from dialects that had 


\section{Pan Wuyun}

been devoiced. The devoicing in the kernel area therefore related only to phonetic conditions and as we discover, it is always the voiced obstruents that were first devoiced. Accordingly we come to conclude that devoicing was an internal sound change of $\mathrm{Wu}$ dialect and would be accelerated under the influences of other dialects.

Languages always influence each other, especially in modern society where the media get involved. Different dialects will all be influenced by the dominant dialect to some extent. For historical linguistics, the vital task is to differentiate between internal sound change and external language borrowing. It is sometimes difficult to tell whether an internal sound change has been influenced by other languages. But as long as it is not a borrowing, historical comparative method is still applicable. Hence, the discussion of sound change admits of two questions: 1) the distinction between two types of influence: language borrowing and internal sound change influenced by external languages; 2) different natural processes simply due to the articulators and sensing organs, the fundamental reason of sound change in human languages. The external influences decide whether the natural process occurs and affect the speed of change.

Labov (1994) put forward three general principles of vowel shifting: 1) In chain shifts, long vowels rise; 2) In chain shifts, short vowels fall; 3) In chain shifts, back vowels move to the front.

The first principle has met almost no counterexamples. A natural process is caused by human speech organs and is independent of external influences. The human buccal cavity is the shape of a trumpet. The space at the back is narrow while the space in the front is large, which is reason why in any human language, back vowels do not outnumber front vowels. Since there is little space at the back, people tend to front the back vowels. Then why will the long vowels rise? The long vowel we refer to here is in its broad sense. When a language has no distinction of long/short vowels, all the vowels in the language are regarded as long vowels. We'll discuss the first principle in the following.

Diag. 11

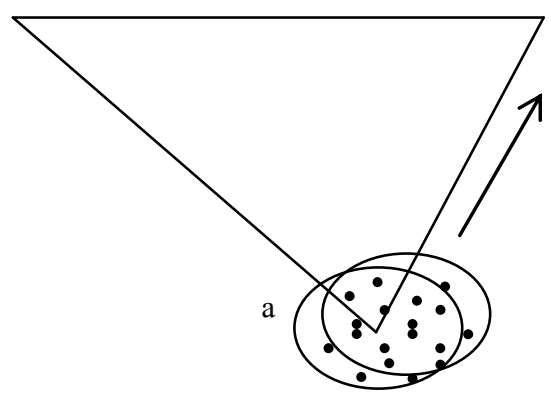

Each phoneme in a speech community is like a statistical distribution of a number of allophones. As shown by the diagram above, the phoneme /a/ comprises of many allophones of different degrees of aperture. As long as the value of a sound falls within the 


\section{On Some Theoretical Issues about Historical Strata Analysis}

phoneme, the sound will still be recognized as /a/ by people of the speech community, though pronounced improperly, say, with the mouth not opening big enough.

Since /a/ is the phonemein the lowest position of the tongue people have to open their mouth wide to articulate it, making it a laborious phoneme to pronounce. As the sound is still intelligible even if someone articulates with a smaller mouth, people tend to pronounce it improperly to save effort, that is, to pronounce with a relatively smaller mouth.

The lower oval in the above diagram represents the phonemic chart of /a/ of the older generation. Sound changes often take place between two generations. When the young generation learns to speak, they tend to pronounce the phoneme inadequately, and the phonemic chart therefore changes to be like the higher oval in diag.11. Since the value of most sounds in the higher oval still falls within the range of phoneme /a/ of the older generation, they do not feel any differences in their pronunciation. However, a few sounds actually go beyond the range. The phonemic chart of /a/ of the young generation is therefore higher than that of the older generation suggesting a relatively higher tongue position. The phoneme, consequently, changes in the direction of the arrow. The long vowels of almost all human languages tend to feature the following course of change:

$$
a>a>0>0>u
$$

Please note that the change from /a/ to /a/ is likely to be the backing instead of the raising of vowels. Since the tongue tilts from the front to the back when people articulate sounds, backing and rising are always correlated. The following is a chart with the formant data of /a/ in English.

Table 8. The Formant Data of /a/ in English (Alan Cruttenden, 2001)

\begin{tabular}{|c|l|l|l|l||}
\hline \multirow{2}{*}{} & \multicolumn{3}{|c|}{ Female } & \multicolumn{2}{c|}{ Male } \\
\cline { 2 - 5 } & $\mathrm{F} 1$ & $\mathrm{~F} 2$ & $\mathrm{~F} 1$ & $\mathrm{~F} 2$ \\
\hline $\mathrm{a}$ & 822 & 1275 & 734 & 1117 \\
\hline $\mathrm{a}$ & 779 & 1181 & 687 & 1077 \\
\hline
\end{tabular}

As shown in the chart, both the frequencies of formant 1 and formant 2 of /a/ are smaller than that of /a/, which means that the tongue position of /a/ is higher than that of /a/.

The rising of long vowels is sometimes affected by the integral phonological structure of the language. Since /a/ is one of the most important phonemes in the phonological system, it is indispensable. If it is raised, a vacancy appears in its position, which leads to other phonemes lowered to fill the vacancy. The drag chain effect may disrupt the principle of long-vowel rising. The question will be discussed below. Now we would like to address the sound change in the Central Plains to elaborate the important principle of natural process.

The Chinese dialects on the Central Plains have long been the authoritative dialect of the Chinese language, which, though having a continuous impact on the peripheral dialects, 
have seldom been subject to the influence of other dialects. Therefore, sound changes of the Chihese dialects can be taken as typical examples of natural process. As recorded in Zhizheng Zhiji (至正直记) by Kong Qi (孔齐) of Yuan (元) Dynasty (1271-1368), “With the proper and elegant sounds, the Northern dialects are regarded as the standard language of the Central Plains, which are spoken in the present-day Bianzhou, Luoyang and Zhongshan (北方声音端正, 谓之中原雅音, 今泣、洛、中山等处是也).” Although Beijing dialect has strata from the Northeast dialects, it shares the similar phonetic framework with Luoyang dialect. As Beijing dialect might be familiar to our readers, we will base our analysis on the discussion of Beijing dialect. Since characters of Division I derive from the long vowels of the Old Chinese, which is exactly the subject for our discussion, we will discuss Division I alone. The rhymes Ge (歌), Yu (鱼), Hou (侯) and You (幽) in Old Chinese became Ge (歌), Mo (模), Hou (侯), and Hao (豪) of Division I respectively in Middle Chinese. Diag. 12 below shows the sound change processes:

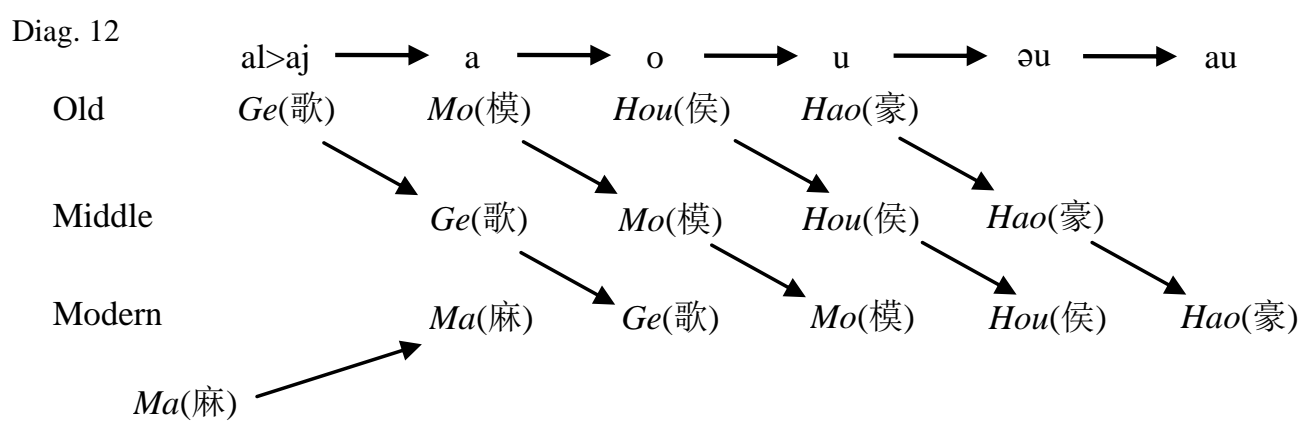

In the final system of Old Chinese, phoneme /a/ belonged to rhyme group $Y u$ (鱼). Its long vowels changed to rhyme Mo (模) of the pronunciation /o/ in Middle Chinese. Being raised, the phoneme left a vacancy in its position, which led to the loss of the coda of rhyme $G e$ (歌) so that the vacancy of /a/ was filled up. As rhyme Mo (模) of Old Chinese was raised to /o/, rhyme Hou (侯) that was originally in the position of /o/ had to move up to /u/, a position formerly belonging to rhyme Hao (豪) of rhyme category You (幽) in Old Chinese. $/ \mathrm{u} /$ is in the highest tongue position and thus cannot be further raised. Hence, rhyme Hao (豪) needed to split to /əu/ in a new chain.

The change of rhyme Ge (歌) was progressing in the meantime, following the principle of vowel rising. When it moved to position /o/, rhyme $M o$ (模) that was formerly in the position was consequently raised to $/ \mathrm{u} /$. Meanwhile, rhyme $M a$ (麻) lost its medial and filled up the vacancy rhyme Ge (歌) left. Rhyme $\mathrm{Hou}$ (侯), whose position was taken by rhyme $M o$ (模), had to split to/əu/, which pushed rhyme Hao (豪) to move to the position /au/.

The change from /ou/ to /au/ was not solely the result of pushing chain, it also conformed 


\section{On Some Theoretical Issues about Historical Strata Analysis}

to the general principles of sound change. First, / // in the /əu/ in Middle Chinese was a short vowel. The change of /o/ to /a/ accords with the principle of short-vowel falling. Second, the two vowels of /ou/ have little difference in terms of sound value. Since /ə/ was a short vowel, this feature of /ou/made it sound like $/ \mathrm{u} /$ in pronunciation, which was unfavorable to phonetic perception. /a/ and / $\mathrm{u} /$ in /au/ differ evidently from each other. When /ou/ changes to /au/, it will no longer mix with the sound /u/. Bernhard Karlgren in his Grammata Serica defines the sound change as "differentiation", which exist in many languages:

$\mathrm{u}>{ }^{\circ} \mathrm{u}>\mathrm{\partial u}>\mathrm{au}$

The change of hus of Old English to the present-day house ([haus]) demonstrates such a sound change process. The following sound changes in the Chinese language again involve high vowels which split away and form a new chain and short vowels that are lowered afterwards:

i> $>$ i>ei>ai (e.g. rhyme $Q i$ (齐) in Cantonese changed from the Old Chinese /i/ to the Middle /Chinese ei/, and to the Modern Cantonese /ai/).

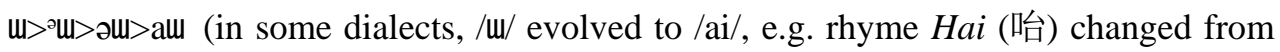
the Old Chinese /W/, to the Middle Chinese /əi/, and finally to the Modern /au/).

The same principle of natural process also applies to $\mathrm{Wu}$ dialect. Diag.13 hows the integral chain shift of Shanghai phonological system:

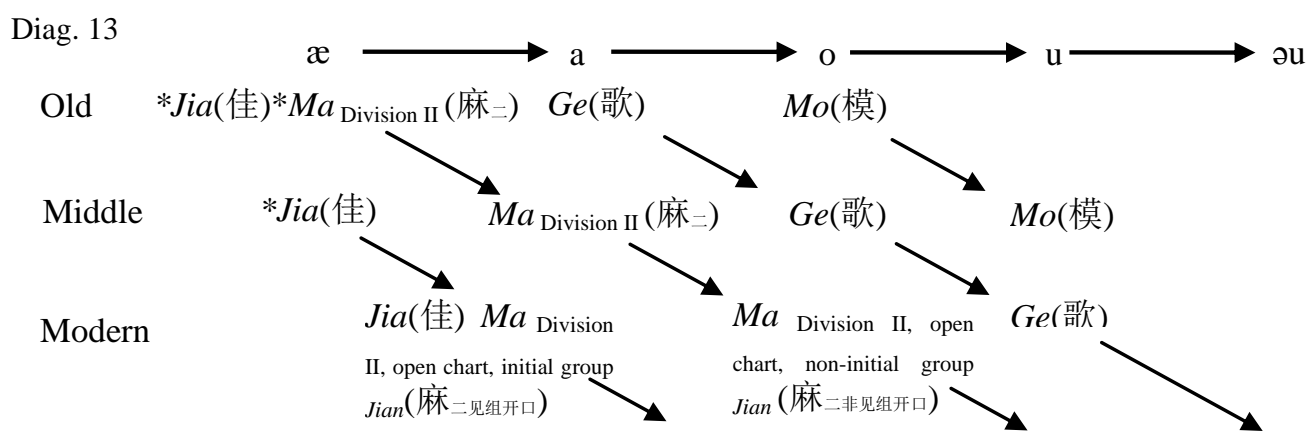

At present, rhyme $M a$ (麻) has evolved to the position /o/ in Shanghai dialect. Nonetheless, according to the survey by Gu Qing (2004), some characters of /-o/ tend to be read as /-u/ in the latest variety of the dialect. As shown by Gu's data, the sound change has two features. First, the common words change first. That is, the sound change occurs in basic words. Second, labial consonants and velar consonants change first. That is, the sound change is restrained with certain phonetic conditions. Both features are inconsistent with those of loanwords. Besides, rhyme $M a$ (麻) is pronounced as /a/ in Chinese Mandarin, and the major peripheral dialects near Shanghai do not have the sound /u/. Therefore, the change from / $/ \mathrm{o} /$ to $/-\mathrm{u} /$ of rhyme $M a$ (麻) in Shanghai dialect happens not because of the 


\section{Pan Wuyun}

influence of other dialects but the result of natural process.

\section{Real time and apparent time}

Linguists used to hold that phonetic changes could not be measured, and thus real-time language changes is barely observed observed in historical linguistics. However, nowadays with the development of sound recording technology and sound lab instruments, the observation and measurement of sound changes has come to reality. The first and second formant frequencies in sound tests show the tongue height as well as its front/back position. If a speech community is given a long-term tracking and sound-recording study, the real-time phonetic changes within the given period can actually be observed through a phonetic experimental analysis of recordings.

However, the long-term real-time tracking is a laborious effort, inefficient and unpractical. Labov (1994) advances an apparent-time method which gains on real time. The phonetic system of a person, once formed, is quite stable and generally free of the impacts from other people. Abnormal pronunciations can be removed if we record people of the same age group and take the mean of their formant frequencies. It is assumed that the phonetic system is formed when an individual is 20 years old. For instance, a group of 80-year-old men born in 1929 can help to reproduce the phonetic features of the speech community around 1949. We divide age groups with five years interval. The speech sounds of the age groups chiefly picture the phonetic features of their respective corresponding times. In the following apparent-time view, the phonetic changes of the age groups collectively represent the real-time change in the given period.

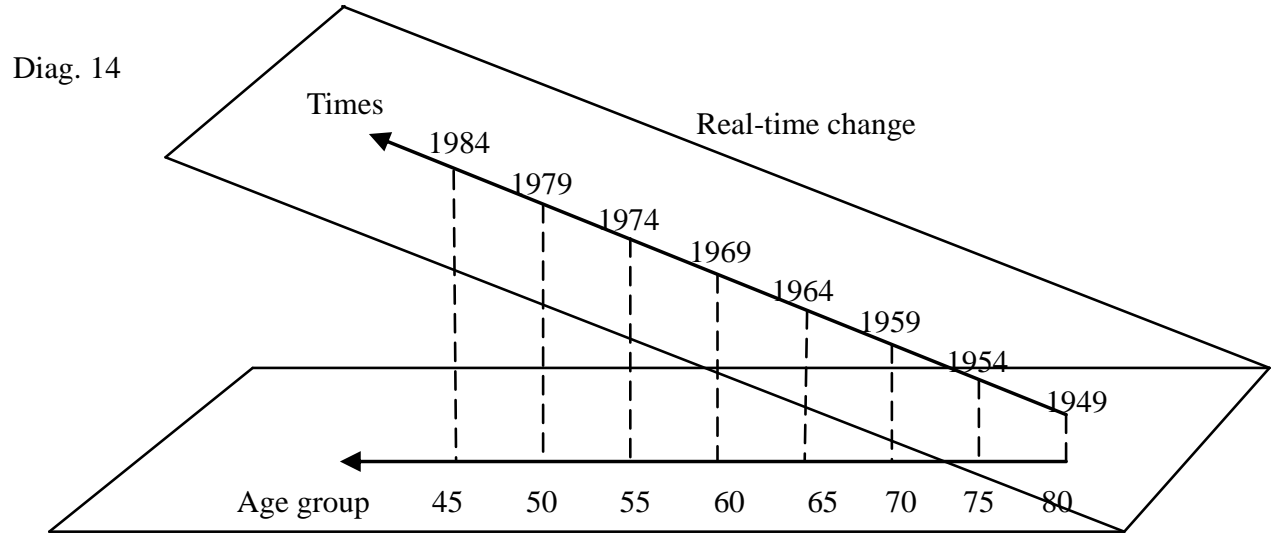

The apparent-time view is in fact the projection of a diachronic-level real-time view on the synchronic plane. It is very like three view drawings in mechanical drawing. 
On Some Theoretical Issues about Historical Strata Analysis

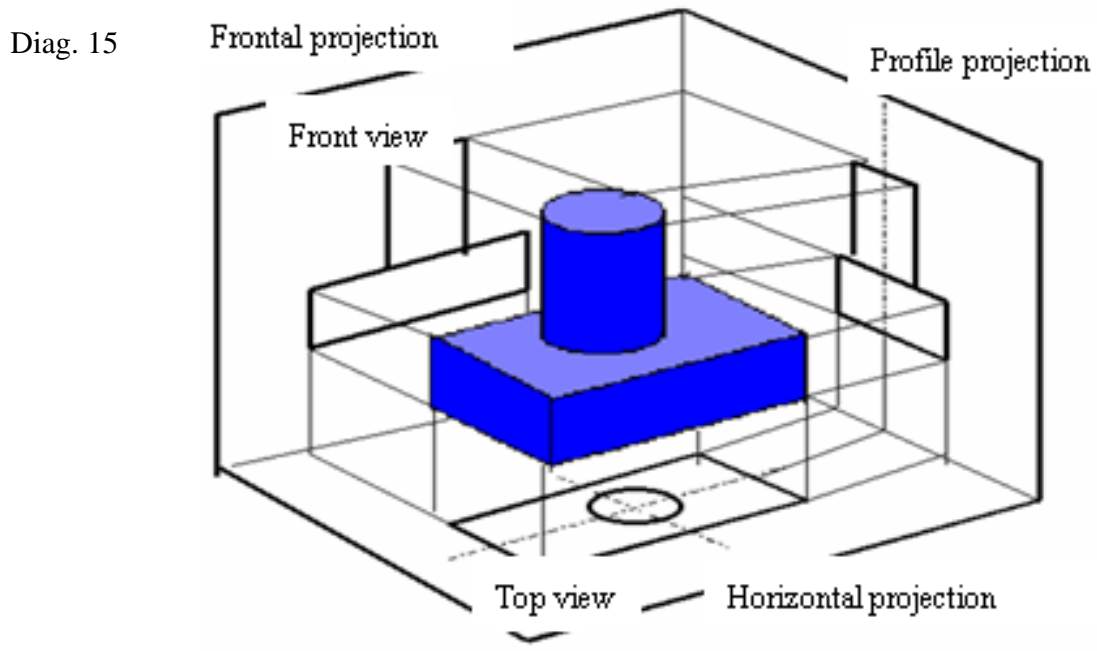

A real object shows different views at different angles. The apparent-time view of Labov is but one of views that describe real-time language changes. Obviously, Labov's definition of apparent time should be expanded so that different apparent-time views are produced, with which we can restore the real-time language change from multiple perspectives.

The apparent-time example below is the projection of a real-time sound change on the dimension of word frequency. A high word frequency will slow down the speed of sound change, which causes high-frequency words left behind in the lagging stratum. An example is rhyme Ge (歌) in Beijing dialect. The rhyme was pronounced as /-ai/ in the Han (汉) Dynasty (206 BC-AD 220). When the coda was lost, the phoneme was backed and raised: ai $>a>a>0>0$. Nonetheless, several high-frequency characters of rhyme $G e$ (歌) were barely changed, such as “大 (dà, 'big')”, “他 (tā, 'he')”, “那 (nà, 'that')”. When other Ge (歌)-rhymed characters moved to phase /-o/, they remained at the phase /-a/. However, there was no position of /a/ in the phonetic system of Chinese language at that time. These characters therefore were assimilated into rhyme $M a$ (麻) which has the closest equivalent sound /-a/. Rhyme Ge (歌) with dental initials split off into /o/ and /a/ in Beijing dialect, which is in truth the projection of real-time sound change on the dimension of word frequency. The pronunciation of $/ 0 /$ and $/ a /$ shows the real-time sound change, $a>0>0$.

Due to different phonetic conditions, an ancient sound class would split off into different sounds. In the ancient Shanghai dialect, characters of rhyme $M a$ (麻) shared the same final. But owing to different initials, they broke away to have different pronunciations. In modern Shanghai dialect, rhyme $M a$ (麻) with a velar initial is pronounced as /a/, and with a labial, dental or glottal initial pronounced as $/ \mathrm{o} /$. Besides, according to the records of Edkins (1853), the rhyme with a glottal initial was also read as / $/$. Different pronunciations of the same rhyme make up a real-time view on the dimension of initials, which can be regarded 


\section{Pan Wuyun}

as the projection of the real-time sound change of the rhyme on the initial dimension. With the apparent-time view, we know about the real-time sound change of the rhyme.

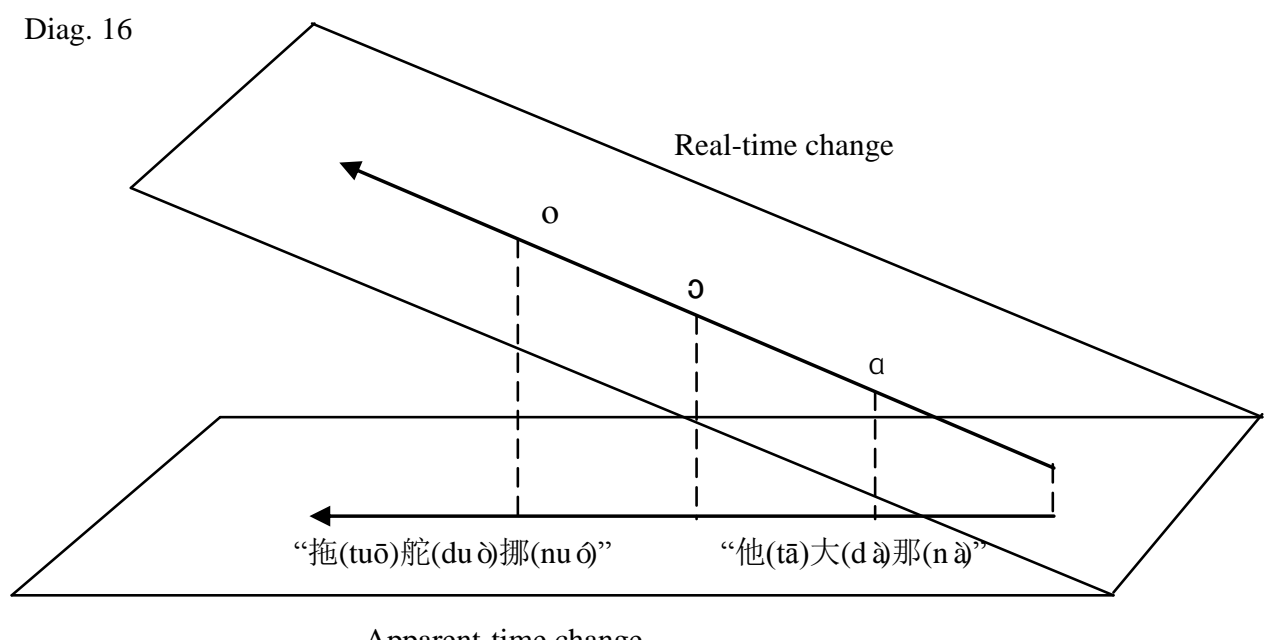

Apparent-time change

Diag. 17

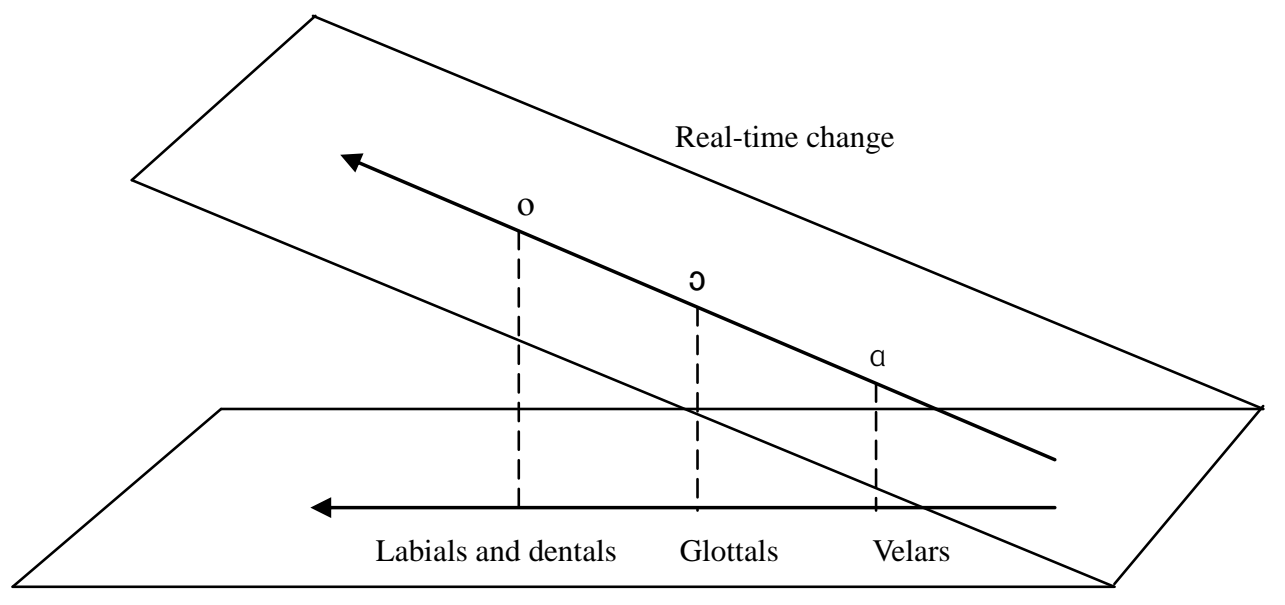

Apparent-time change

When a sound change occurs in an ancient sound class, the speed at which each dialect of that dialect continuum changes differs. The modern pronunciation actually presents one phase of the real-time sound change. The following diagram shows the pronunciations of rhyme $G e$ (歌) with a dental initial in the counties of Wenzhou dialect continuum. 


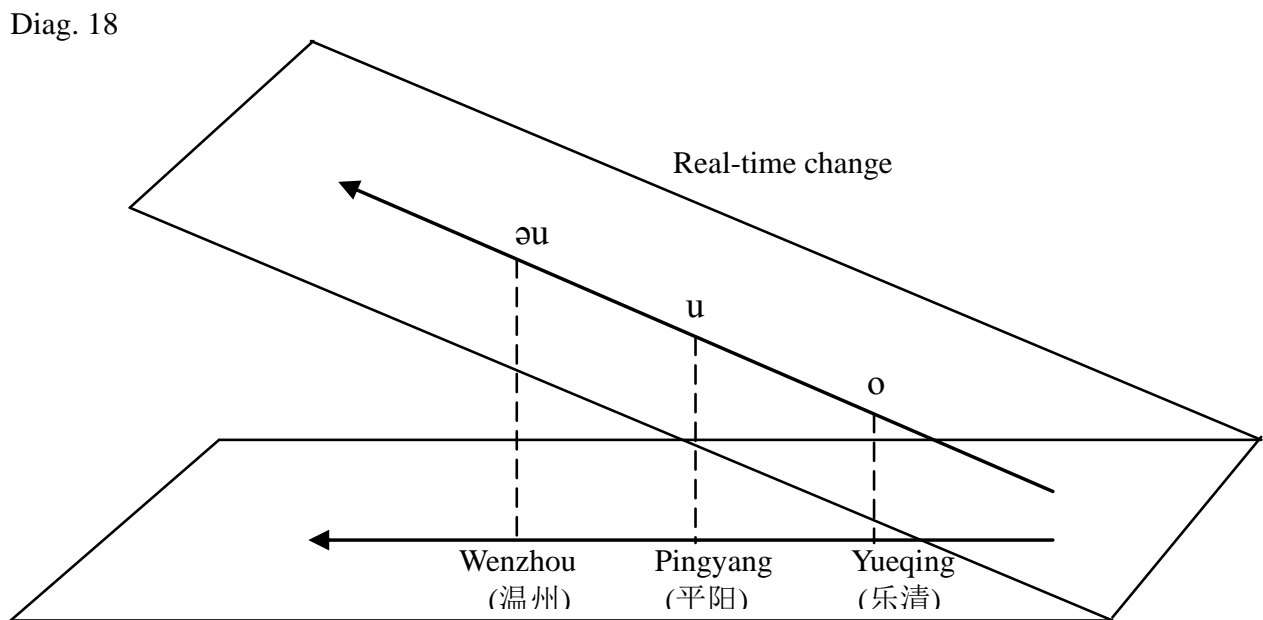

Annarent-time change

As shown in diag.18, Yueqing (乐清) dialect changes at the slowest speed and the pronunciation of the rhyme remains in the phase /o/, while Wenzhou dialect changes the fastest and the pronunciation has progressed to /au/. The modern pronunciations /ou/, / $/ \mathrm{d}$ and $/ \mathrm{o} /$ of Wenzhou (温州), Pingyang (平阳) and Yueqing (乐清) respectively form an apparent-time view on the geographical dimension, which is the synchronic projection of the real-time sound change of $\mathrm{o}>\mathrm{u}>\mathrm{\partial u}$ on the dimension of geography.

With the above types of apparent-time views, we can obtain the temporal sequence of sound changes. For instance, apparent-time views on the dimension of the age of informants show the period in which the sound change occurs. As the sound change speed is related to word frequency, the dimension of word frequency, to some extent, presents sounds in the lagging stratum. Phonetic conditions and sound change speed are correlated too. Therefore, the analysis of pronunciation principles tell what phonetic condition accelerates sound changes. The geographical dimension cannot directly show the temporal sequence of sound changes. Nonetheless, as the pronunciations of different dialects all descend from the same sound in the ancient times, they collectively construct an apparent-time view which demonstrates definitely a natural process. Thus when we arrange the pronunciations in accordance with the natural process, we can roughly obtain the direction of the real-time sound change.

\section{References}

Cao Zhiyun, et al. 2000. On Chuqu Dialect of Wu dialect [M]. Tokyo: Kohbun Co..

Dai Shaoming. 2003. A Preliminary Research on Tiantai Dialects [M]. Beijing: China Social Sciences Press. 


\section{Pan Wuyun}

Gu Qin. 2004. The Investigation and Analysis of the Phonetic Evolution of the Newest Variety of Shanghai Urban District Dialect [D]. Shanghai: Shanghai Normal University.

Pan Wuyun. 1999. Sound Archives for Wenzhou Dialects [M]. Shanghai: Shanghai Education Press.

Qian Nairong. 1992. A Study on Contemporary Wu dialect [M]. Shanghai: Shanghai Education Press.

Wang Danian. 1988. The Historical Changes of Consonantal Codas in Burmese [J]. Minority Languages of China, 2:41-50.

Wang Jingliu \& Chen Xiangmu. 1983. Collection of Minority Language Studies: Investigation on the Tones of Dai Language [C]. Kunming: Chinese Department of Institute of Minority Languages, Yunnan Province.

Cruttenden, Alan. 2001. Gimson's Pronunciation of English [M]. Beijing: Foreign Language Teaching and Education Press.

Edkins, Joseph. 1853. A Grammar of Colloquial Chinese: As Exhibited in the Shanghai Dialect [M]. Shanghai: London Mission Press.

Labov, William. 1994. Principles of Linguistic Change: Internal Factors [M]. Cambridge, MA: Blackwell. Whitney, William Dwight. 1867. Language and the Study of Language [M]. New York: Charles Scribner \& Co..

(Translated by Wu Yue, School of International Studies, Zhejiang University, Hangzhou, China) 